\title{
CONTRIBUIÇÕES DA PESQUISA-AÇÃO NO TRABALHO COTIDIANO: A PRÁTICA DE PROFISSIONAIS DA EDUCAÇÃO EM UM CENTRO DE ATENDIMENTO INCLUSIVO
}

\author{
Gilberto Ferreira da Silva ${ }^{1}$ \\ Unilasalle, Canoas, Brasil \\ Raquel Schlemer König \\ Unilasalle, Canoas, Brasil \\ Natacha Scheffer \\ IPA, Porto Alegre, Brasil
}

\begin{abstract}
Resumo. Este trabalho faz parte de uma pesquisa em andamento, intitulada "Formação continuada de professores: a pesquisa-ação colaborativa em contextos de práticas educativas inclusivas ( $2^{\mathrm{a}}$. Fase)", financiada pelo Conselho Nacional de Desenvolvimento Científico e Tecnológico (CNPq). Para este momento, optamos pela pesquisa etnográfica, com o intuito de explorar uma das etapas do processo de vivência da pesquisa-ação. Trata-se do momento de observação das ações educativas conduzidas pelos profissionais no cotidiano do trabalho em um Centro de Atendimento Educacional Especializado, vinculado à rede municipal de ensino. Para além das observações, trabalhamos com registros da reunião de discussão e análise das observações produzidas, analisando como os profissionais do centro veem suas práticas no cotidiano do trabalho e como se repensam a partir desse processo. Consideramos os estudos de Silva e Nörnberg (2013), Franco (2012) e Tardif (2000) para construir o apoio teórico. Nesta etapa da pesquisa foi possível evidenciar quanto o refletir sobre o que se faz e como se faz na prática educativa cotidiana contribui para desvelar, no trabalho em equipe, tanto as fragilidades quanto os acertos do grupo de profissionais. Tal dinâmica permitiu um processo de sensibilização aos problemas, mobilizando para a construção de soluções. De outro modo, a reflexão sobre a prática desestabiliza e provoca desconfortos, pois acaba por impulsionar a revisão de aspectos já consolidados, como por exemplo, a postura profissional.
\end{abstract}

Palavras-chave: formação continuada; pesquisa-ação, formação em serviço, educação inclusiva.

\section{CONTRIBUCIONES DE LA INVESTIGACIÓN-ACCIÓN AL TRABAJO COTIDIANO: LA PRÁCTICA DE PROFESIONALES DE LA EDUCACIÓN EN UN CENTRO DE ATENCIÓN INCLUSIVO}

\begin{abstract}
Resumen. Este trabajo es parte de un estudio en curso titulado "Formación continuada de profesores: investigación-acción colaborativa en contextos de prácticas educativas inclusivas" ( $2^{\mathrm{a}}$ Fase), financiado por el Consejo de Desarrollo Científico y Tecnológico Nacional (CNPq). Con este fin, optamos por la investigación etnográfica, con el propósito de explotar una de las etapas del proceso de vivencia de la investigación-acción. Se optó por la observación de las actividades educativas llevadas a cabo por los profesionales en el trabajo cotidiano en un Centro de Atención para la Educación Especializada,
\end{abstract}

1 Adelcio Machado dos Santos - Universidade Alto Vale do Rio do Peixe. Caçador, Brasil. Endereço: Rua Prof. Egidio Ferreira, $\mathrm{n}^{\circ}$ 271, Bloco “E”, Apto. 303 CEP: 88090-500, Florianópolis (SC) Brasil. E-mail: adelciomachado@ gmail.com. 
vinculado al sistema escolar municipal. Además de las observaciones, trabajamos con los registros de los grupos de discusión y consideración de las observaciones formuladas. Para atender nuestros propósitos, nos propusimos las siguientes preguntas: Cómo perciben los profesionales del centro sus prácticas en el trabajo diario y cómo se lo replantean a partir de este proceso Consideramos los estudios de Silva y Nornberg (2013), Franco (2012) y Tardif (2000) para construir el soporte teórico. Por lo tanto, en esta etapa de la investigación se hizo evidente reflexionar sobre cómo lo que se hace en la práctica educativa cotidiana ayuda a revelar, en el trabajo en equipo, tanto las debilidades como los éxitos del grupo de profesionales.

Esta dinámica permitió un proceso de conciencia de los problemas, dinamizando la construcción de soluciones. De otro modo, la reflexión sobre la práctica desestabiliza y causa malestar, pues acaba por impulsar la revisión de aspectos ya consolidados, como por ejemplo, la actitud profesional.

Palabras clave: Educación Continuada; Investigación-Acción, Servicios de Capacitación, Educación Inclusiva.

\title{
CONTRIBUTIONS OF ACTION RESEARCH IN THE DAILY WORK: THE PRACTICE OF PROFESSIONAL EDUCATION IN AN INCLUSIVE SERVICE CENTER
}

\begin{abstract}
This work is part of an ongoing study, titled "Continuing teacher education: collaborative action research in contexts of inclusive educational practices (2nd Phase)" funded by the National Scientific and Technological Development Council (CNPq). For this aim we opted for ethnographic research, for the purpose of making use of one of the stages of the process of action-research experience. We opted for observing the daily educational activities carried out by professionals in a Specialized Educational Service Center, linked to the municipal school system. Besides of the observations, we worked with the discussion groups. To meet our aims, we set the following questions: How do the professionals of the center see their daily work practices and do how they rethink about them? We consider the studies of Silva and Nörnberg (2013), Franco (2012) and Tardif (2000) to build the theoretical framework. Thus, in this stage of the research it became clear the need to reflect about how the daily educative practice helps to reveal the weakness and also the success of the professionals. This dynamic allowed a process of awareness of the problems, mobilizing for building solutions. Otherwise, the reflection on practice destabilizes and causes discomfort, because it ultimately boost reviewing aspects already consolidated, such as the professional attitude.
\end{abstract}

Keywords: Continuing Education; Action Research, Training Services, Inclusive Education.

\section{Introdução}

Este trabalho faz parte de uma pesquisa em andamento, intitulada "Formação continuada de professores: a pesquisa-ação colaborativa em contextos de práticas educativas inclusivas (2a . Fase)", financiada pelo Conselho Nacional de 
Desenvolvimento Científico e Tecnológico (CNPq). A pesquisa foi organizada em três momentos distintos. O primeiro deles coloca em evidência a busca pela literatura no campo da formação de professores e o uso da pesquisa-ação como estratégia metodológica de construção de alternativas para a formação continuada. No segundo momento, centramos nossa atenção na discussão sobre formação continuada de professores e a educação inclusiva, procurando localizar o estado da arte neste campo específico, afim de subsidiar as preocupações do grupo de profissionais da educação e pesquisadores acadêmicos envolvidos diretamente na pesquisa original. E, finalmente, no terceiro momento, há a sistematização e a problematização do processo de vivência da pesquisa-ação com o grupo de profissionais da educação de um Centro de Atendimento Educacional Especializado.

Neste estudo, optamos por realizar uma discussão explorando uma das etapas do processo de vivência da pesquisa-ação com os profissionais do centro. Essa etapa consistiu em um momento de observação das ações de atendimento educacional especializado, conduzidas pelos profissionais no cotidiano do trabalho, seguido pelo registro da reunião de discussão que se realizou após o término das observações. Para alcançar os propósitos pretendidos, partimos das seguintes questões: Como os profissionais do centro veem suas práticas no cotidiano do trabalho? E como eles as repensam a partir do processo de vivência da pesquisa?

Nesse sentido, apresentamos inicialmente uma discussão sobre os princípios da pesquisa-ação que orientam a realização do trabalho de investigação, situando especificamente o processo de construção dessa etapa da pesquisa que subsidia a elaboração deste trabalho; em um segundo momento analisamos o que revelam os registros produzidos pelo grupo de pesquisadores e profissionais da educação do centro.

Para tratar dos princípios da pesquisa-ação, destacamos que nestes últimos anos viemos experimentando de diferentes modos as contribuições desse tipo de pesquisa como proposta metodológica para o desenvolvimento de estudos e igualmente como forma de colocar a pesquisa a serviço dos profissionais da Educação Básica (Silva e Sorribas, 2014; Silva e Nörnberg, 2013; Silva, Nörnberg e Pacheco, 2012). A ruptura do lugar clássico de pesquisador é um dos grandes avanços que se pode observar ao se procurar seguir os princípios da pesquisa-ação. A ampliação do uso da pesquisa-ação ocorreu a partir da década de 1980, período em que André (2001) situa mudanças nas pesquisas em educação, caracterizadas pela redução de estudos centrados em fatores extraescolares e aumento de estudos centrados em questões intraescolares. Para a autora, esses estudos passavam a se debruçar sobre o cotidiano escolar, focalizando questões como “... o currículo, as interações sociais nas escolas, as formas de organização do trabalho pedagógico, a aprendizagem da leitura e da escrita, as relações de sala de aula, a disciplina e a avaliação ...” (André, 2001, p. 53). Em sua consolidação, 
Zeichner e Noffke (1998) destacam que a pesquisa-ação tem se desenvolvido por meio de vertentes significativamente diversificas. Neste estudo, especificamente, tomamos como referência primeira a proposição de Kurt Lewin (1890-1947) e procuramos, dinamicamente, colocar em ação as quatro etapas metodológicas preconizadas pelo pesquisador. Partimos do "diagnóstico", buscando conhecer e reconhecer quais são as questões emergentes e importantes para a construção de soluções. Passamos para o "planejamento", que resulta das escolhas e opções definidas pelo coletivo de profissionais; portanto, um momento importante para eleger o que é mais urgente e significativo para o trabalho. Após, seguimos para a "aplicação do planejamento", em que é posta em prática a proposta de ação e, ao mesmo tempo, coloca-se em movimento a dinâmica de acompanhamento e observações das práticas; isso constitui registros dessa ação, que acabam por subsidiar a etapa seguinte. Chegamos à "avaliação", concretizada pela retomada da experiência feita, baseada principalmente nos registros produzidos pelos "observadores" da prática, assim, reiniciando o processo, realizando o movimento espiralado sugerido por Kurt Lewin ${ }^{2}$.

Outro aspecto que emerge de nossas experiências investigativas até o momento é o fato de que a metodologia permite uma entrada na "intimidade" das práticas educativas que ainda não havíamos experimentado em trabalhos, seguindo outros pressupostos metodológicos. Essa dimensão é possível porque a pesquisa-ação trabalha diretamente com o indivíduo que vivencia a ação, colocando-o igualmente na condição de pesquisador de sua própria ação. Nesse sentido, a metodologia acaba por subsidiar o "professor-pesquisador" para que se instrumentalize e se aproprie de ferramentas teóricas e técnicas, potencialmente com condições de contribuir para o aperfeiçoamento das ações educativas. Ainda que este seja um processo que demanda tempo e exige um acompanhamento a médio e longo prazos, é possível observar os ganhos e avanços nas próprias discussões com os coletivos envolvidos na pesquisa, como é o caso do grupo de professores-pesquisadores (profissionais do centro) deste estudo.

Nossa aposta na pesquisa-ação como método revitaliza-se e demonstra potencial para sua aplicação no campo da formação continuada de professores. Percebemos que ainda precisa-se construir uma base de experiências em que a teoria e a prática possam efetivamente nutrir os avanços das práticas docentes e, por consequência, a qualidade da educação que se deseja. O exercício do olhar como estratégia autoformativa no processo da pesquisa-ação, desdobrado nos registros (observações com características etnográficas), revela dimensões desse fazer e traduzem o que chamamos de "intimidade" do fazer docente, que raramente acessamos.

\footnotetext{
${ }^{2}$ Descrevemos cuidadosamente estas quatro etapas em outro trabalho que se encontra disponível para acesso, consultar: Silva e Nörnberg (2013).
} 


\section{Opções metodológicas}

Para análise do que revelam os registros produzidos pelo grupo de pesquisadores e profissionais da educação do centro, a pesquisa apoiou-se na etnografia. $\mathrm{Na}$ alusão de Geertz (1989, p. 20) "Fazer etnografia é como tentar ler (no sentido de 'construir uma leitura de') um manuscrito estranho, desbotado, cheio de elipses, incoerências, emendas suspeitas e comentários tendenciosos, escrito não com os sinais convencionais do som, mas com exemplos transitórios de comportamento modelado."

Nesse sentido, a perspectiva etnográfica orientou a produção dos registrou e a forma com que o olhar foi direcionado para o planejamento posto em prática. Nesse processo prevaleceu a abordagem qualitativa.

Os educadores pesquisadores envolvidos com o registro das observações foram seis. A adesão ao processo de produção das observações se deu de forma voluntária, considerando principalmente a disponibilidade para observar e ser observado.

Em reunião específica, foi organizado um cronograma de observações, delimitando uma semana como período de referência para a realização dos registros. Três bolsistas juntaram-se ao trabalho, dos quais uma realizou três observações. Assim, obtivemos no total 11 registros de diferentes práticas educativas do centro. Os educadores pesquisadores observaram e foram observados, produzindo um registro desse processo ${ }^{3}$.

Como forma de discussão e reflexão sobre os achados dos registros, foi realizada uma reunião na qual todas as observações foram expostas e discutidas. Sendo assim, tratamos neste artigo de informações diretamente tomadas dos 11 registros, como também dos dados obtidos pelas anotações produzidas, durante a reunião de discussão, seguindo a perspectiva etnográfica.

\section{Análise e discussão dos resultados: o que revelam os registros produzidos}

Para a análise dos dados partimos de uma leitura prévia, procurando construir eixos temáticos. $\mathrm{Na}$ análise preliminar, selecionamos aqueles que apresentam maiores potenciais que nos permitam compreender o objetivo proposto neste trabalho. Assim, as condições de infraestrutura dos espaços e as práticas no atendimento educacional especializado são dois eixos que ganharam uma maior ênfase.

\footnotetext{
${ }^{3}$ Para instrumentalizar os professores-pesquisadores foi realizado um seminário sobre Observação Etnográfica, em que se abordou os usos da etnografia na pesquisa em educação e se exercitou estratégias de registro de observações nessa perspectiva. É interessante destacar que essas formações se inserem de forma objetiva dentro de um fim maior, que é o de compreender como se traduzem as práticas e como os próprios profissionais do centro veem seu trabalho.
} 


\section{Dos espaços da infraestrutura: travessias do velho para o novo}

A infraestrutura do centro vive um momento de transição, ou, como preferimos chamar, "travessia do velho para o novo", uma vez que o prédio original é oriundo de uma escola pública municipal abandonada; portanto, as condições físicas do prédio são bastante precárias. A alusão à travessia se justifica pelo fato de que se encontra em construção um novo prédio, no qual metade da obra já foi entregue pela empresa responsável e a outra está em fase de execução. Assim, o velho e o novo convivem nas práticas educativas cotidianas, que por sua vez demarcam e influenciam-nas, conforme podemos observar nos registros que seguem:

Logo ao entrar neste espaço, que mede aproximadamente $15 \mathrm{~m}^{2}$ tem-se de início, uma desagradável sensação de abandono e de relativa tristeza. As paredes já quase sem cor devido a inexorável ação do tempo, uma janela do tipo basculante e de ferro carcomido, coberta por uma cortina azul-claro transparente, situada no lado esquerdo de uma porta de um azul-escuro desbotado, também velha. $\mathrm{O}$ chão de parquê irregular, com alguns tacos soltos e já sem brilho e o teto de um branco esmaecido, de onde pende dois pontos de luz bruxuleante. Em toda a sala paira uma atmosfera de desolação, decadência e de envelhecimento, causando em quem a contempla uma sensação de nostalgia e comiseração $\left(\mathrm{PE}^{4}{ }^{4}\right)$.

O olhar do educador que registra o seu próprio espaço de trabalho traduz no exercício de ver e rever o cotidiano a experiência de viver e atuar. É o olhar de quem está imerso, mas que pela escrita se promove como observador e passa, de um modo diferente, a se apropriar mais uma vez deste espaço tão familiar e, ao mesmo tempo, distante. A autoria exercitada igualmente pela escrita tece a descrição e a interpretação do ambiente, onde o futuro anunciado carrega a esperança do novo que se vislumbra: "É importante salientar que a atual realidade estrutural em breve será modificada, visto que um novo prédio está em fase de conclusão, o qual contemplará as especificidades e necessidades deste atendimento" (PE1). Nesta mesma direção outros profissionais assim dão seguimento à descrição do ambiente do trabalho:

O ambiente onde se realizam as sessões de atendimento é uma sala com divisórias, pois o espaço é dividido com a secretária do centro... Ela é composta por três computadores dispostos um ao lado do outro. Há livros de histórias infantis; jogos e brinquedos pedagógicos à disposição dos alunos. Existe uma mesa circular para o trabalho em grupo com cadeiras distribuídas ao redor, assim como um armário de madeira para que seja colocado os materiais da profissional. Percebi que a sala não comporta mais que dois cadeirantes em virtude de seu tamanho (PE5).

\footnotetext{
${ }^{4}$ Para identificar a autoria dos registros, usamos PE (Profissional da Educação), seguido do número correspondente do registro, BIC (Bolsista de Iniciação Cientifica), igualmente seguido por um número de identificação, BAT (Bolsista de Apoio Técnico) e RR (Registro de Reunião).
} 
O estímulo para que realizassem um tipo de escrita/registro em que a característica etnográfica fosse referência acabou por evidenciar arranjos de palavras, revelando uma busca cuidadosa pelo sentido, assim como um exercício de maior liberdade ao fazer uso dessas palavras. A escrita historicamente constitui-se um desafio para os educadores, principalmente quando é reveladora de práticas de um coletivo ao qual se pertence. É possível perceber que os registros adensam-se e ganham riqueza em detalhes, primando pela descrição cuidadosa, característica peculiar da escrita etnográfica. Nesse aspecto encontra-se um dos elementos importantes da pesquisa-ação, quando lança mão da estratégia da escrita como processo autoformativo. No processo de construção do registro, dá-se conta do entorno, das dificuldades, das diferenças entre o olhar que vai rompendo com o cotidiano, esmiuçando detalhes, cartografando a rotina. Assim registra outro educador: "Sala do novo prédio, branca, bem iluminada e arejada, preenchida com mobiliário - 4 mesas, cadeiras em uso e empilhadas, prateleira com instrumentos musicais, 2 armários, caixas de papelão. Pouco espaço livre” (PE4).

Começam a conviver em um mesmo espaço ambientes físicos diferenciados, o que antes aparecia como uma dificuldade para o desenvolvimento do trabalho dá lugar a uma nova perspectiva, mais positiva, mais animadora. "O espaço físico apresentava boa iluminação, prédio novo, sala ampla com uma divisória ao meio, uma pia na entrada da sala à esquerda" (PE3), descreve outro educador. É possível observar que a mudança da infraestrutura começa a mexer com a postura dos profissionais. Assim, é preciso reconhecer que mudanças nesse quesito estão acontecendo, e, portanto, é preciso que ocorram deslocamentos dos discursos, assim como a forma como se vê o cotidiano das práticas educativas. Um estudo desenvolvido por Andrade e Raitz (2012) em escolas públicas do Paraná e de Santa Catarina aponta para a importância da participação da comunidade e da família no processo educativo, assim como destaca quanto as classes populares esmeram-se por buscar melhores condições de estudo, tanto no que diz respeito a professores qualificados, educação reconhecidamente de qualidade quanto em relação a boa infraestrutura do espaço físico oferecido pela escola. Andrade e Raitz, amparando-se nos estudos de Lahire e Charlot, enfatizam:

... a família tem uma grande responsabilidade na formação e desenvolvimento do filho (aluno), pois são eles que acompanham toda a história desses indivíduos, suas primeiras experiências de vida, por exemplo, são adquiridas na família. Neste sentido, é inegável, segundo estes autores, a contribuição dos pais para o desenvolvimento humano, seja para o sucesso ou para o fracasso escolar dos filhos (Andrade e Raitz, 2012, p. 11).

Inegavelmente, o grupo de profissionais reconhece a importância do espaço diferenciado para a qualificação das ações educativas, mas para além desse aspecto é possível inferir que o investimento na infraestrutura significa também o reconhecimento 
do Centro Educacional de Atendimento Especializado na organização estrutural e hierárquica da rede municipal de ensino, ou seja, é a assunção do centro na conquista de um lugar de caráter mais definitivo no organograma organizacional da rede pública. No início do trabalho com este grupo de educadores (cinco anos atrás) era frequente ouvir a queixa da falta de condições de infraestrutura, um discurso corrente em meio ao grupo. Ainda que pareça serem recentes as melhorias e igualmente os efeitos delas nas posturas profissionais e ações educativas, é possível anunciar um reposicionamento discursivo do coletivo de profissionais, procurando por outras razões que possam justificar possíveis problemas enfrentados no cotidiano do centro, não mais agora atribuídos à ausência de infraestrutura. Assim, observamos no registro que a descrição da sala é positiva, entretanto, o espaço, segundo avaliação do educador, continua sendo reduzido para o trabalho desenvolvido. Talvez devêssemos lançar um olhar mais cuidadoso para essas elaborações que vão realizando igualmente travessias, já não mais tão materializadas, mas travessias discursivas que acabam mantendo o velho discurso da queixa. Isso remete para a transferência de uma situação velha para outra que também não é nada nova. O "espaço físico não é apropriado". Continua não sendo (?).

De outro modo, se confrontarmos essa lógica de pensamento, em que se reconhece o lugar da infraestrutura de qualidade para a sua equivalente qualidade nas práticas educativas, é no mínimo provocativo a conclusão de um estudo realizado pelos pesquisadores Sátyro e Soares (2007), tomando dados do Censo Escolar para descrever as condições de infraestrutura das escolas do Ensino Fundamental no contexto brasileiro. Assim sintetizam os pesquisadores os achados da pesquisa:

O primeiro resultado é que as condições materiais do ensino melhoraram muito entre 1997 e 2005, embora os resultados escolares, tanto em termos de repetência como em termos de aprendizado, não tenham mudado muito neste mesmo período. O segundo é que não há grandes diferenças de infraestrutura ou formação docente entre as escolas estaduais e privadas, embora existam grandes diferenças entre estas duas e as municipais. Este é um resultado curioso, já que não há grandes diferenças de resultado entre municipais e estaduais, mas há, sim, grandes diferenças entre estas duas e as privadas. Estes dois resultados colocam em dúvida o impacto de melhorias de infraestrutura ou de formação docente sobre os resultados escolares (Sátyro e Soares, 2007, p. 7).

De um lado, lançamos mão dos registros produzidos pelos educadores em suas práticas, que valorizam as mudanças na infraestrutura do espaço de trabalho cotidiano ocupado por esses profissionais da educação no centro de atendimento. De outro lado, um estudo de maior alcance e com dados estatísticos comprovam de forma mais direta e "objetiva” a pouca influência, ou quase nenhuma, dessas condições nos processos de aprendizagem e sua consequente melhoria na qualidade da educação pública. No caso específico colocado em discussão nesta pesquisa, ainda é cedo para corroborarmos com 
essa direção de pensamento, entretanto, os alertas pelos estudos dos pesquisadores destacados remetem para que se considere e questione como lidamos com as avaliações e a produção do discurso sobre as práticas.

Essa discussão desperta para um cuidado necessário ao se produzir a análise de dados nessa direção. Esperamos poder em outros trabalhos explorar de forma mais aprofundada essas questões que emergem nesta análise. Partimos do pressuposto que, ao se trabalhar com o fenômeno da educação como objeto de estudo, devemos, no mínimo, considerar que estamos a trabalhar com um objeto complexo, que exige do pesquisador competência para articular diferentes possibilidades de interpretação e suas diferentes formas de tratamento. Além disso, igualmente, é preciso considerar que cada realidade e contexto em que se dá o levantamento de dados exige interpretações próprias e localizadas. De outro modo, não tem sido recorrente, no campo da educação, estudos que contemplem a produção de informações no campo das relações entre qualidade de educação e condições de infraestrutura das escolas públicas (Sátyro e Soares, 2007). Eis um campo emergente de estudos.

\section{Sobre as práticas educativas no atendimento educacional especializado}

Um dos princípios que emergiu da reflexão, mobilizada pelo acesso aos registros dos colegas, sintetiza um pressuposto que se encontra instituído no coletivo de profissionais da educação que atuam no centro. A afirmação colhida durante a reunião traduz como os profissionais da educação se veem: "Que o trabalho no centro é sustentado em um trabalho de equipe e é um lugar de diálogo.” (RR).

Como lugar de diálogo, o registro da sequência esclarece o momento em que os professores-pesquisadores refletem juntos sobre um dos processos de trabalho, denominado Triagem, em que acontece o primeiro contato do estudante com o centro, momento no qual os pais fazem uma entrevista e a criança indicada para atendimento é observada. Essa etapa é realizada em equipe, constituída de forma multidisciplinar:

A professora questionou o processo da triagem, que acontece em um tempo de trinta a quarenta minutos e que às vezes, através da documentação enviada pela escola, relatando o porquê este aluno é encaminhado ao Centro, já se tem uma ideia de que não é necessário atendimento especializado. Os colegas não concordaram, lembrando que o educador que escreve o encaminhamento na escola nem sempre coloca ou sabe colocar a real situação do aluno e só uma triagem com os profissionais especializados é que pode, de fato, comprovar se este aluno precisa ou não dos cuidados do Centro. (RR) 
Esta educadora, ao opinar que às vezes o indivíduo não necessita de atendimento e que é possível constatar isso por meio dos documentos enviados pela escola, é levada pelos seus colegas a pensar que somente o especialista, no caso, o fonoaudiólogo, é capaz de analisar e constatar dificuldades na fala, assim como somente um psicopedagogo é capaz de perceber dificuldades da aprendizagem. O que é possível observar nesta manifestação é o fato de que, mesmo inserido em um contexto institucional em que o trabalho de equipe na perspectiva multidisciplinar e interdisciplinar está posto como prática cotidiana, os "lugares" de conhecimento ainda são demarcados por uma visão disciplinar. Há uma tensão aqui que revela a contradição entre o desejado e o vivido, ou seja, de como se traduz o idealizado para a ação cotidiana. $\mathrm{O}$ disciplinamento que parece ganhar evidência neste discurso, em detrimento da perspectiva multi-interdisciplinar, ganhou maior arrebatamento por parte dos outros profissionais presentes na reunião de discussão dos dados, e assim trazemos um outro registro:

A professora confirmou que em uma documentação enviada pela escola parecia que o aluno não precisava de atendimento do Centro, mas após uma entrevista constatou que sim, era necessário. Por fim, todos concordaram que é preciso avaliar a ficha que é um instrumento, mas que às vezes o educador faz uma leitura equivocada do aluno e por isso a importância da entrevista. (RR)

É o coletivo que acaba por construir uma síntese da forma como se processa o encaminhamento prático; é preciso considerar os dados produzidos pelo educador da escola ao fazer seu encaminhamento, assim como é preciso que os profissionais do centro construam uma síntese de forma mais amparada na documentação e nas estratégias de conhecimento do aluno em observação no processo denominado de Triagem. O que se consolida neste movimento é a ideia de que o trabalho em equipe no cotidiano, como espaço de formação e autoformação, permite o repensar daquilo que se faz na educação. A grande questão, quando se quer efetivamente transformar e qualificar as ações educativas, é construir a oportunidade do encontro sistematizado e planejado para que as trocas e interações entre os profissionais aconteçam. Em um outro trabalho, em que nos propusemos a refletir sobre as concepções destes mesmos educadores sobre educação inclusiva, constatamos que:

A educação inclusiva acontece, sobretudo, quando se inventa, na escola, práticas pedagógicas que apostam na experiência como um princípio organizador do trabalho pedagógico e na pedagogia da procura, cuja aposta é a que busca, na e pela relação, constituir processos de construção de relações consigo, com o outro, com o conhecimento, com o mundo. (Silva e Nörnberg, 2013, p. 670).

Os espaços de trocas rotineiras já instituídas no centro de atendimento, como é o caso da Triagem, acaba por deslocar os profissionais da educação para um trabalho 
prioritariamente pensado como equipe, como coletivo, onde é iniciado o trabalho, mas que terá continuidade por um outro profissional/colega, e que este processo em breve estará retornando, seja para o próprio profissional em sua especificidade, seja em discussões no coletivo. Não basta simplesmente realizar o "diagnóstico" nessa etapa do processo prático; é preciso ter presente que o centro assume a responsabilidade de trabalhar com essa criança, com esse estudante, para oferecer melhores condições para o seu desenvolvimento cognitivo, social e cultural. O que é possível observar nessa dinâmica é que o trabalho rompe com a clássica prática, na qual o professor especializado raramente se comunica e interage com o outro profissional, ou seja, as áreas do conhecimento pouco interagem e, consequentemente, pouco aprendem umas com as outras. Nesse sentido, percebe-se na escrita dos registros nas observações dos professores-pesquisadores outros momentos de intervenção com os alunos nos atendimentos ocorridos no centro:

Cinco alunos, entre 6 e 9 anos, diferentes deficiências. Dois professores. Inicia o atendimento: alunos convidados a deitar em colchonetes, professor conduz atividade, vai contar uma história, música de meditação ao fundo, luz apagada, professora auxilia. Sentado em uma cadeira, inicia a narrativa, convoca os alunos a percorrerem mentalmente com ele os percursos narrados na história (uma viagem), busca os alunos ao contar, projetando-se corporalmente em direção dos mesmos. Os alunos, alguns de olhos fechados, escutam a história e a música. Duas crianças fazem movimentos paralelos: bate os pés, arranha o colchonete. A narrativa se encerra, finda a viagem... luz acesa, agora sentados nos colchonetes, fazem a partilha das vivências ocorridas durante a história, auxiliados pelos professores. (PE4)

Primeiramente a atividade proposta foi um jogo onde os alunos teriam que juntar sílabas e formar palavras. A cada palavra sugerida, batiam palmas para identificar o número de sílabas. Todos se envolveram na atividade, dois deles com mais dificuldade, demonstraram insegurança e medo de errar. (PE2)

Dessa maneira, o grupo pensa e sugere novas propostas de trabalho, construindo novos saberes que são pensados coletivamente, esse é o processo da pesquisa-ação, além, obviamente, da socialização desses conhecimentos produzidos (Franco, 2012). Também durante a socialização foi possível repensar o lugar ocupado pelo centro na rede municipal de ensino no que diz respeito às questões de educação inclusiva.

Como lugar de diálogo, também cabe ressaltar que cada educador possui a sua própria personalidade e as suas experiências adquiridas, pois ao ensinar coloca muito de si, das suas vivências, estruturando, aos poucos, a construção do profissional, do educador, intervindo significativamente na aprendizagem. Tardif explica que: 
Ao evocar qualidades desejáveis ou indesejáveis que quer encarnar ou evitar como professor, ele se lembrará da personalidade marcante de uma professora do quinto ano, de uma injustiça pessoal vivida na pré-escola ou das intermináveis equações impostas pelo professor de química no fim do segundo grau. A temporalidade estruturou, portanto, a memorização de experiências educativas marcantes para a construção do Eu profissional e constitui o meio privilegiado de chegar a isso. (Tardif, 2000, p. 216)

Dessa forma, os registros aqui analisados refletem na forma pessoal que o educador organiza e constitui o seu trabalho. Nessa direção, ainda segundo Tardif (2000, p. 216) "[...] uma boa parte do que os professores sabe [sic] sobre o ensino, sobre os papéis do professor e sobre como ensinar provém de sua própria história de vida, principalmente de sua socialização enquanto alunos". Por isso, ao se trabalhar com a pesquisa-ação, considera-se quanto o grupo consegue ir amadurecendo no próprio processo de vivência da pesquisa e assumindo as decisões do coletivo como compromisso pessoal e não como meros acertos públicos sem valor e significado pessoal. Nessa direção, Franco enfatiza que, “Ao considerarmos a participação, é muito comum encontrarmos professores que ainda não vivenciaram processos participativos, cooperativos, processos de co-gestão.” (2012, p. 271).

Os relatos foram revelando e evidenciando possibilidades de conhecer as práticas de cada profissional e suas formas de tradução e atribuição de significado, pois, ao produzir o registro, em um primeiro momento, e, em um segundo, discuti-lo oralmente com os colegas de forma pública, exigiu-se um nível de maturidade que acabou surpreendendo o próprio grupo. Entre os momentos de tensão ao ver a tradução da prática pessoal em texto de outro colega, afloram discordância com termos, conceitos e nomenclaturas até então sequer imaginados pelo protagonista da prática. Trata-se de um fazer que não pertence mais exclusivamente ao agente educativo responsável, mas que ganha publicidade, tornando a ação do centro de atendimento o resultado de um coletivo no sentido mais estrito da palavra. Passado o primeiro "impacto", o diálogo começa a tomar conta, para dar margem a um novo processo.

O processo de reflexão crítica e coletiva impõe ao grupo afrontamentos, constrangimentos, equívocos. Isso exige a construção de uma maturidade do grupo, que impõe um efetivo trabalho de controlar e conduzir as emoções que emergem num processo de mudança; de se confrontar com a cultura organizacional das escolas que nem sempre se organizam para favorecer um clima propício à emancipação e autonomia de seus membros. (Franco, 2012, p. 273).

Por meio dessa construção da maturidade do grupo, pela socialização e leitura dos registros, é possível concluir que a educação é um processo mediante o qual o 
professor não pode limitar-se a um trabalho solitário, mas precisa munir-se de conceitos que o levem a mudança, pela partilha com outros colegas, contribuindo para que possam repensar colaborativamente a prática educativa. Enfim, encerramos a análise das observações com as próprias questões levantadas ao final de uma das reuniões, considerando que em educação lidamos com o inacabado, com processo de travessias, reconstruindo-se e refazendo-se com as novas situações vivenciadas: Qual é a nossa proposta? Qual é o papel do centro? Estamos de fato auxiliando o estudante? Quais os benefícios para cada aluno?

\section{Considerações finais}

Ao colocarmos em evidência a preocupação por conhecer como se dão as práticas educativas em movimento no cotidiano da ação docente no Centro de Atendimento Educacional Especializado, amparados pelos princípios da pesquisa-ação, acabamos por ingressar em um outro universo, que impele a ruptura de práticas educativas isoladas, e estas passam a ser socializadas nos espaços coletivos, traduzidas pelo "olhar" do outro (colega). A estratégia de observação e registro das práticas entre os colegas, conforme anunciado, permitiu, ao procedermos à análise dos registros, dar visibilidade maior para alguns aspectos, os quais passamos a sintetizar a seguir.

$\mathrm{O}$ primeiro deles refere-se à uma discussão que carece de mais investimentos por parte dos pesquisadores em educação. A temática a exigir esse investimento é a das relações entre infraestrutura e educação. Poderia o discurso corrente sobre a falta de condições ideais para o desenvolvimento do trabalho educativo de qualidade justificar a inexistência dele? Estaria a categoria de profissionais da educação amparando-se em um discurso do senso comum para explicar a falta de resultados qualificados no trabalho educativo? Ou os instrumentos e as estratégias de avaliação da aprendizagem das práticas docentes encontram-se distanciadas do universo escolar e seu contorno social, cultural e econômico, que exigem novos modos de se pensar a educação, principalmente quando tomada como objeto de estudo?

No nosso caso específico, os profissionais do centro estudado revelam valorizar as melhorias na qualidade de infraestrutura do local e acreditar que essas mudanças passarão a oferecer melhores condições de trabalho. Portanto, chegaria-se a uma equação equivalente: melhores condições de infraestrutura física levariam à maior qualidade do trabalho educativo oferecido.

O segundo aspecto diz respeito ao trabalho propriamente dito dos profissionais e como eles veem seu trabalho. Observou-se uma espécie de hiato entre o que se faz e como se faz o trabalho educativo cotidiano no centro. De um lado, o imaginário sobre a prática docente, revelado pelos discursos, acaba não se traduzindo de fato em ações 
coerentes com o que se espera de um profissional. Esse aspecto remete-nos para um outro elemento, igualmente importante, que é o enfrentamento de situações no campo da subjetividade e da própria postura profissional que acabou sendo posta em discussão. A prática da metodologia da pesquisa-ação exige dos participantes maturidade profissional para mudanças que envolvem também questões da subjetividade. A pergunta que foi dirigida aos pesquisadores que trabalham com esse tipo de metodologia: estamos preparados para acompanhar e contribuir em processos dessa envergadura na pesquisa em educação?

\section{Referências}

Andrade, C. e Raitz, T. R. (2012). As possíveis razões do sucesso escolar em duas escolas públicas. Anais. IX ANPED SUL, Seminário de Pesquisa em Educação da $\begin{array}{llll}\text { Região Sul. } & 16 \mathrm{p} & \text { Recuperado de }\end{array}$ http://www.ucs.br/etc/conferencias/index.php/anpedsul/9anpedsul/paper/viewFile/1 595/139, em 18 de abril de 2015.

André, M. (2001). Pesquisa em educação: buscando o rigor e qualidade. Cadernos de Pesquisa, 113, 51-64. Recuperado de http://www.scielo.br/pdf/cp/n113/a03n113.pdf, em 20 de março de 2015.

Franco, M. A. S. (2012). Práticas colaborativas na escola: as possibilidades da pesquisaação pedagógica. XVI ENDIPE - Encontro Nacional de Didática e Práticas de Ensino - UNICAMP - Campinas.

Geertz, C. (1989). A intepretação das culturas. Editora Guanabara-Koogan, Rio de Janeiro.

Sátyro, N. e Soares, S. (2007) A infra-estrutura das escolas brasileiras de ensino fundamental: um estudo com base nos censos escolares de 1997 a 2005. Texto para discussão no 1267. Brasília, IPEA, 2007. Recuperado de http://repositorio.ipea.gov.br/bitstream/11058/1752/1/TD_1267.pdf, em 20 de março de 2015.

Silva, G. F., Nörnberg, M. e Pacheco, S. M. (2012). Processos formativos a partir de práticas inclusivas na educação básica. Inter-ação (UFG. Online), 37, 91-112.

Silva, G. F. e Nörnberg, M. (2013). Sentidos e significados da educação inclusiva: o que revelam os profissionais do Centro de Capacitação em Educação Inclusiva e Acessibilidade (CEIA/Canoas). Revista Diálogo Educacional (PUCPR. Impresso), 13, 647-668.

Silva, G. F.; Sorribas, J. D. C. (2014). Formação de professores para a educação inclusiva em contextos de diversidade cultural. Conhecimento \& Diversidade, v. 5, 51-62. 
Tardif, M. e Raymond, D. (2000). Saberes, tempo e aprendizagem do trabalho no magistério. Educação \& Sociedade, ano XXI, 209 (73), Dezembro. 219-244.

Zeichner, K. e Noffke, S. (1998). Practitioner research. In V. Richardson (Edi.) Handbook on of research teaching. $4^{\mathrm{a}}$. ed. American Education Research Association.

Data de recepção: 05/07/2015

Data de revisão: 01/11/2015

Data do aceite: $23 / 11 / 2015$ 
